\title{
STRUCTURE AND MECHANICAL PROPERTIES \\ OF HIGH-ENTROPY AlCuNiFeTi AND AICuNiFeCr \\ ALLOYS PRODUCED BY MECHANICAL ACTIVATION FOLLOWED BY PRESSURE SINTERING
}

\author{
A. I. Yurkova, ${ }^{1}$ V. V. Chernyavskii, ${ }^{1,3}$ and V. F. Gorban',2
}

UDC 620.22:620.187.22:543.442.3

\begin{abstract}
$X$-ray diffraction, scanning electron microscopy, and micromechanical tests are employed to study the phase and structural transformations in the $\mathrm{Al}-\mathrm{Cu}-\mathrm{Ni}-\mathrm{Fe}-\mathrm{Ti}$ and $\mathrm{Al}-\mathrm{Cu}-\mathrm{Ni}-\mathrm{Fe}-\mathrm{Cr}$ equiatomic powder compositions during mechanical activation and subsequent pressure sintering. The mechanical properties of the high-entropy alloys are examined as well. It is revealed that the AlCuNiFeTi and AlCuNiFeCr nanocrystalline high-entropy alloys produced by mechanical activation consist of supersaturated substitutional solid solutions with bcc crystal structure. It is established that the alloys become three-phase after sintering and consist mainly of bcc solid solutions and an insignificant amount (to 5\%) of two fcc solid solutions with different lattice parameters. It is shown that the sintered AlCuNiFeTi and AlCuNiFeCr alloys are characterized by high strength, and their Vickers microhardness reaches $11.2 \pm 0.3 \mathrm{GPa}$ and $9.5 \pm 0.25 \mathrm{GPa}$, respectively.
\end{abstract}

Keywords: high-entropy alloy, mechanical activation, pressure sintering, structure, phase composition, mechanical properties.

\section{INTRODUCTION}

Conventional commercial metallic alloys consist of one major solvent element and a small amount of several doping additives required to improve the service properties. These alloys are thermodynamically unstable in certain conditions. Hence, phase transformations may occur in their structure at elevated temperatures or during heat treatment; this is unacceptable as can impair their service properties. Excessive amounts of doping elements result in the formation of numerous intermetallics, deteriorating the properties and complicating analysis of the alloys.

Many industries need new structural and tool materials with improved performance and application properties. According to many scientists and engineers, this issue can be solved with high-entropy alloys (HEAs) [1-3]. High-entropy alloys belong to a new class of metallic materials. They are multicomponent alloys, containing from five to thirteen metallic elements. The content of each element depends on the number of components in an alloy and can vary between 5 and 35 at.\% [2,3]. The high mixing entropy of alloy components is regarded as

${ }^{1}$ National Technical University of Ukraine 'Kyiv Polytechnic Institute', Kyiv, Ukraine. ${ }^{2}$ Frantsevich Institute for Problems of Materials Science, National Academy of Sciences of Ukraine, Kiev, Ukraine.

${ }^{3}$ To whom correspondence should be addressed; e-mail: vadikv13@gmail.com.

Translated from Poroshkovaya Metallurgiya, Vol. 55, Nos. 3-4 (508), pp. 37-52, 2016. Original article submitted September 21, 2015. 
beneficial for forming alloys with simple crystal structures. This ensures appropriate thermal stability of the phase composition and structural state and thus mechanical, physical, and chemical properties of the alloys. Therefore, HEAs contain substitutional multi-element solid solutions remaining in place even after heat treatment, on the one hand, and acquire a unique combination of mechanical characteristics, on the other hand.

The HEAs are peculiar in that they do not have a major element; i.e., all elements of the composition taken in equal molar parts are major. Entropy increases sharply in high-entropy alloys $(\Delta S=13-19 \mathrm{~J} / \mathrm{mol} \cdot \mathrm{K})$, but these systems remain stable. A solid solution containing substitutional elements with different atomic radii, electron structures, and properties substantially distorts the crystal lattice, thus promoting significant solid-solution hardening, decreasing diffusion activity, and increasing thermal stability. According to [4-6], HEAs have low free energy so that the solid solution remains stable when subjected to subsequent heat treatment.

The formation of simple solid solutions with increased entropy and a great number of equiatomic chemical elements essentially influences properties of the alloy: strength, ductility, thermal stability, and corrosion and wear resistance increase at both room and higher temperatures $[1,3,6]$. The simple structure of solid solutions is easy to examine and helps eliminate brittleness inherent in ordered compounds.

The high-entropy alloys can be fabricated with the same techniques as used for conventional alloys: casting, melt quenching, mechanical activation (MA), and deposition of films and coatings [1,7]. Each technique has its advantages and disadvantages. Mechanical activation produces more homogenous microstructure than melt quenching does and allows forming parts of different shapes and sizes in the last step. Greater homogeneity of solid solutions when processed at room temperature is the main MA advantage over casting, especially for multicomponent alloys produced from starting components with different melting points. Moreover, MA develops a nanocrystalline structure, improving the alloys' mechanical properties. For actual use of mechanically activated HEAs, it is important that the powder is further consolidated and the alloy retains the phase composition and structural state required to improve the mechanical properties.

The objective of this paper is to examine the phase composition, structure, and mechanical properties of $\mathrm{AlCuNiFeTi}$ and $\mathrm{AlCuNiFeCr}$ equiatomic alloys, produced by MA of a multicomponent powder mixture followed by pressure sintering.

\section{Experimental Procedure}

The starting materials were $\mathrm{Al}, \mathrm{Cu}, \mathrm{Ni}, \mathrm{Fe}, \mathrm{Ti}$, and $\mathrm{Cr}$ powders of high purity (99.8\%), with particles $\leq 45 \mu \mathrm{m}$ in size, taken in equal molar parts (20 at.\% each). The alloy components were selected so as to form stable solid solutions in multicomponent alloys in accordance with $[1,4,8]$. The high mixing entropy $\left(\Delta S>11 \mathrm{~J} \cdot \mathrm{K}^{-1} \cdot \mathrm{mol}^{-1}\right)$ is the predominant factor, controlling the formation of alloys. The mixing enthalpy was $-22 \mathrm{~kJ} / \mathrm{mol}<\Delta H<7 \mathrm{~kJ} / \mathrm{mol}$ and the difference of atomic radii $\delta<8.5 \%$.

Considering $[1,4,8]$ and Tables 1 and 2, we determined the mixing entropy with the Boltzmann equation:

$$
\Delta S=R \ln (n),
$$

where $R$ is the gas constant and $n$ is the number of chemical elements in the alloy. The difference of atomic radii $\delta$ was found as

$$
\delta=100 \sqrt{\sum_{i=1}^{n} c_{i}\left(1-r_{i} / \bar{r}\right)^{2}}, \bar{r}=\sum_{i=1}^{n} c_{i} r_{i},
$$

where $c_{i}$ and $r_{i}$ are the atomic percent and atomic radius of the $i$-th element (Table 1). The mixing enthalpy $\Delta H$ was calculated as

$$
\Delta H=\sum_{i=1, i=j}^{n} \Omega_{i j} c_{i} r_{i}, \Omega_{i j}=4 \Delta_{\mathrm{mix}}^{\mathrm{AB}},
$$

where $\Delta_{\text {mix }}^{\mathrm{AB}}$ is the mixing enthalpy of the binary alloys (Table 2). For selected components of the Al-Cu-Ni-Fe-Ti and $\mathrm{Al}-\mathrm{Cu}-\mathrm{Ni}-\mathrm{Fe}-\mathrm{Cr}$ alloys, the mixing entropy of each alloy is $13.38 \mathrm{~J} \cdot \mathrm{K}^{-1} \cdot \mathrm{mol}^{-1}$, being much higher that $\Delta S$ 
TABLE 1. Structures, Average Atomic Radii, and Melting Points of Elements in the AlCuNiFeTi and $\mathrm{AlCuNiFeCr}$ Alloys

\begin{tabular}{|c|c|c|c|c|}
\hline Element & Structure & $\begin{array}{c}\text { Average atomic } \\
\text { radius, } \mathrm{nm}\end{array}$ & Melting point, $\mathrm{K}$ & VEC, e/a \\
\hline $\mathrm{Al}$ & $\mathrm{fcc}$ & 0.1432 & 933 & 3 \\
$\mathrm{Cu}$ & $\mathrm{fcc}$ & 0.1278 & 1356 & 11 \\
$\mathrm{Fi}$ & $\mathrm{fcc}$ & 0.1246 & 1726 & 10 \\
$\mathrm{Fe}$ & $\mathrm{bcc}$ & 0.1241 & 1811 & 4 \\
$\mathrm{Ti}$ & $\mathrm{hcp}$ & 0.1460 & 1933 & 6 \\
$\mathrm{Cr}$ & $\mathrm{bcc}$ & 0.1249 & 2148 & \\
\hline
\end{tabular}

Note. VEC—valence electron concentration.

TABLE 2. Bonding Energy of Potential Atomic Pairs [9] of the AlCuNiFeTi and AlCuNiFeCr Alloys, kJ/mol

\begin{tabular}{|c|c|c|c|c|c|c|}
\hline Element & $\mathrm{Al}$ & $\mathrm{Cu}$ & $\mathrm{Ni}$ & $\mathrm{Fe}$ & $\mathrm{Ti}$ & $\mathrm{Cr}$ \\
\hline $\mathrm{Al}$ & - & -1 & -22 & -11 & -30 & -10 \\
$\mathrm{Cu}$ & -1 & - & 4 & 13 & -9 & 12 \\
$\mathrm{Ni}$ & -22 & 4 & - & -2 & -35 & -7 \\
$\mathrm{Fe}$ & -11 & 13 & -2 & - & -17 & -1 \\
$\mathrm{Ti}$ & -30 & -9 & -35 & -17 & - & -7 \\
$\mathrm{Cr}$ & -10 & 12 & -7 & -1 & -7 & - \\
\hline
\end{tabular}

TABLE 3. Mixing Entropy, Mixing Enthalpy, Atomic Radius Difference, and VEC for the AlCuNiFeTi and AlCuNiFeCr Alloys

\begin{tabular}{|c|c|c|c|c|}
\hline Alloy & $\Delta S, \mathrm{~J} \cdot \mathrm{K}^{-1} \cdot \mathrm{mol}^{-1}$ & $\Delta H, \mathrm{~kJ} \cdot \mathrm{mol}^{-1}$ & $\delta, \%$ & $\mathrm{VEC}, \mathrm{e} / \mathrm{a}$ \\
\hline AlCuFeNiTi & 13.38 & -17.6 & 7.16 & 7.2 \\
AlCuFeNiCr & 13.38 & -4.0 & 4.9 & 7.6 \\
\hline
\end{tabular}

for conventional alloys. The data obtained (Table 3) correspond to the conditions required to form stable HEA solid solutions.

To identify the type of crystal lattice of the solid solution, we used VEC in the alloy, characterizing the average number of valence electrons in the system. It is shown $[4,8]$ that solid solutions with an fcc crystal lattice form at VEC $\geq 8 \mathrm{e} / \mathrm{a}$, and bcc solid solutions appear at $\mathrm{VEC} \leq 6.87 \mathrm{e} / \mathrm{a}$.

The valence electron concentration was determined with the equation provided in [8]:

$$
\mathrm{VEC}=\sum_{i=1}^{n} c_{i}(\mathrm{VEC})_{i},
$$

where $(\mathrm{VEC})_{i}$ is the valence electron concentration of the $i$-th component (Table 1). The VEC calculated for the $\mathrm{AlCuNiFeTi}$ alloy is $7.2 \mathrm{e} / \mathrm{a}$ and for $\mathrm{AlCuNiFeCr}$ is $7.6 \mathrm{e} / \mathrm{a}$; according to $[4,8,10]$, this is evidence of solid solutions with bcc and fcc lattices that formed in the system in question.

The powder mixture was mechanically activated in a planetary-ball mill. The grinding jars rotated at $580 \mathrm{rpm}$. A weighed portion of the powder mixture was determined by the powder-to-ball weight ratio $(1: 10)$. The experiment employed grinding jars and balls $10 \mathrm{~mm}$ in diameter, made of hardened steel of ShKh6 grade. To avoid oxidation, cold welding, and excessive agglomeration, the powder was ground in purified gasoline.

To decrease porosity, increase density, and preserve nanostructure, the mechanically activated powder was consolidated by sintering at $5 \mathrm{GPa}$ and $1073 \mathrm{~K}$ for $30 \mathrm{~min}$ using a D0044 hydraulic press for the synthesis and 
sintering of superhard materials or D0044 high-pressure apparatus (Ryazan' High-Pressure Apparatus Factory, Russia).

The shape and size of particles and the microstructure of powder and consolidated alloys were examined with a REMMA-101A scanning electron microscope (SELMI JSC, Ukraine). The alloy's chemical composition was determined with energy dispersive X-ray microanalysis (EDX) using SEM.

The phase composition and structure of the powder mixture at different MA steps and of the AlCuNiFeTi and $\mathrm{AlCuNiFeCr}$ alloys following pressure sintering were studied with an Ultima IV X-ray diffractometer (Rigaku Co., Japan) in monochromatic $\mathrm{Cu}-K_{\alpha}$ radiation. The monochromator was a graphite single crystal on the path of a diffracted beam. The diffraction patterns were taken by stepwise scanning at $2 \theta=20-120^{\circ}$. The scanning angle was $0.04^{\circ}$ and goniometer angular velocity was $2 \% \mathrm{~min}$. The X-ray diffraction data were processed with the PowderCell 2.4 software for full-profile analysis of X-ray spectra.

The size of crystallites (coherent scattering domains (CSDs)) and microstresses in the powder alloys were determined from the broadening of diffraction peaks in compliance with the conventional procedure [11], excluding instrumental broadening. Silicon powder deposited on the compacts was used as reference for determining the lattice parameters of the solid solution.

The mechanical characteristics of the alloys (hardness $H_{\mathrm{IT}}$, reduced elastic modulus $E_{\mathrm{r}}$, and indentation elastic strain $\varepsilon_{\mathrm{es}}$ and associated yield stress $\sigma_{\mathrm{es}}$ ) were determined by continuous indentation (Berkovich diamond pyramid with a $65^{\circ}$ rake) using a Micron Gamma machine (National Aviation University, Aerospace Institute, Ukraine) [12] in accordance with the procedure described in [13]. The load $F$ was $1.5 \mathrm{~N}$. Automatic loadingunloading lasted $30 \mathrm{sec}$, load applied to the indenter $(F)$ and depth of indenter penetration $(h)$ into the test material being recorded in the process. The loading, holding, and unloading $F-h$ curve was being plotted in parallel. The load $F$ was determined with an accuracy of $10^{-3} \mathrm{~N}$ and indenter penetration depth $h$ with an accuracy of $\pm 2.5 \mathrm{~nm}$. The Vickers microhardness of the alloys was also measured using a PMT-3 microhardness meter (LOMO JSC, Russia) under $F=1.5 \mathrm{~N}$ in compliance with standard technique.

\section{RESULTS AND DISCUSSION}

Structure and Phase Composition of AlCuNiFeCr and AlCuNiFeTi Equiatomic High-Entropy Alloys Formed in Mechanical Activation Process. In initial MA stages, the starting powder particles are refined and coldwelded as they experience severe plastic deformation induced by the grinding balls. In the early MA step, this gives rise to coarse particles (Fig. 1 $a, c$ ) since the welding proceeds faster than grinding, producing powder agglomerates with a layered structure (Fig. $1 b, d$ ). After being ground in a planetary-ball mill for $30 \mathrm{~min}$, the $\mathrm{Al}-\mathrm{Cu}-\mathrm{Ni}-\mathrm{Fe}-\mathrm{Cr}$ and $\mathrm{Al}-\mathrm{Cu}-\mathrm{Ni}-\mathrm{Fe}-\mathrm{Ti}$ powder particles reach $10-13 \mu \mathrm{m}$ in average size. There are, however, finer $(3-4 \mu \mathrm{m})$ and very coarse (up to $200 \mu \mathrm{m}$ ) particles of the layered composites (Fig. 1 $a-d$ ). Multiple refinement and cold welding processes during MA gradually lead to finer powder particles with a smoother morphology. The powder refinement promotes mutual diffusion of metallic elements, reducing the time needed for interpenetration of various powder components. The AlCuNiFeCr layered structure disappears in $5 \mathrm{~h}$ of MA and a homogenous structure without clear boundaries between the alloy components shows up (Fig. 1f). Note that longer grinding is required to produce homogenous AlCuNiFeTi alloy (Fig. 1h). The particles are almost equiaxed in shape (Fig. 1e, g), with an average size of 5-6 $\mu \mathrm{m}$, but there are coarser particles reaching $45 \mu \mathrm{m}$. The fractional composition of the powder alloys does not change with longer grinding times, indicating that the refinement and cold welding processes are balanced and the mechanical activation process is complete [14].

Electron microprobe analysis, whose results are summarized in Table 4, was used to check how homogeneous the alloy chemical composition was. The nominal content of each element in the starting powder mixture was 20 at.\%, and deviation of each alloy element from the nominal content was $<2.5$ at.\%. Although the quantitative electron microprobe analysis is not highly accurate, the results allow a conclusion that the alloy has sufficiently homogenous chemical composition.

The X-ray diffraction spectra (Fig. 2a) show transformations that proceed at different MA stages in the starting $\mathrm{Al}-\mathrm{Cu}-\mathrm{Ni}-\mathrm{Fe}-\mathrm{Ti}$ equiatomic powder mixture. The diffraction pattern for the starting quinary mixture 


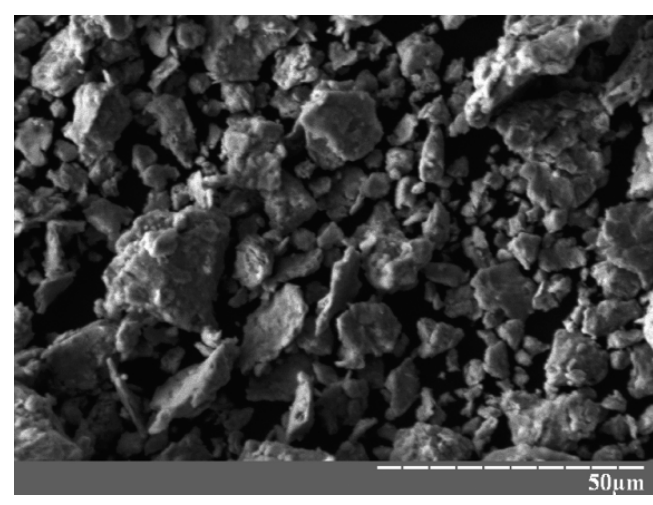

$a$

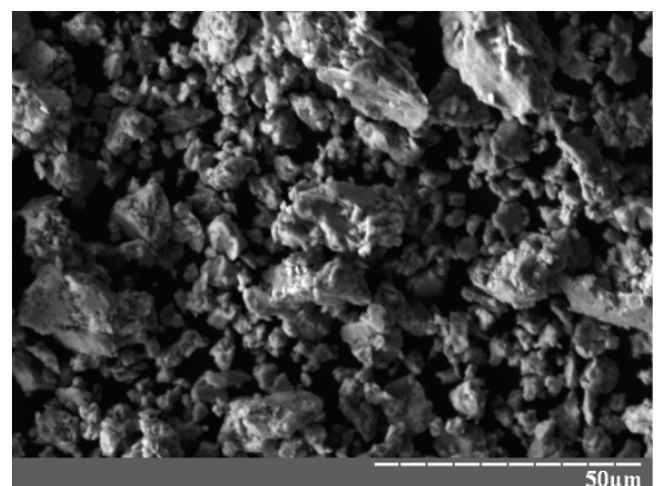

$c$

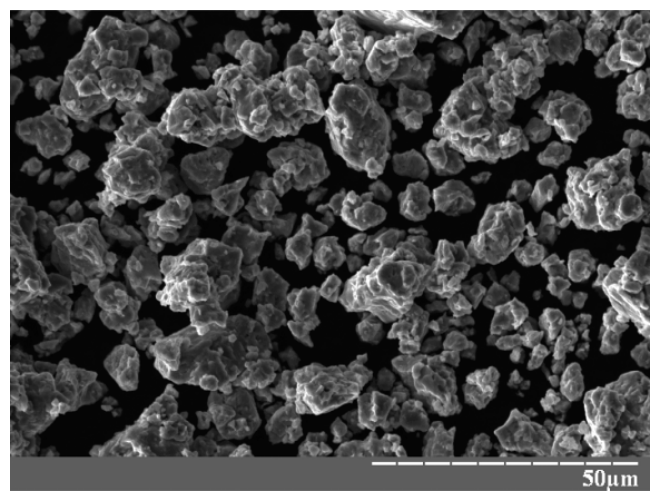

$e$

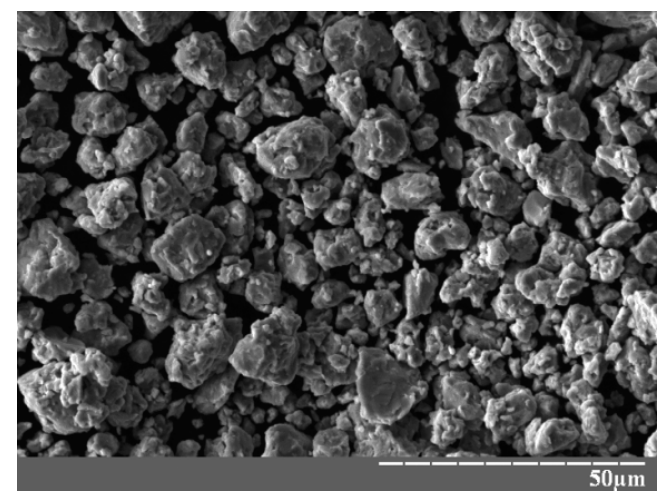

$g$

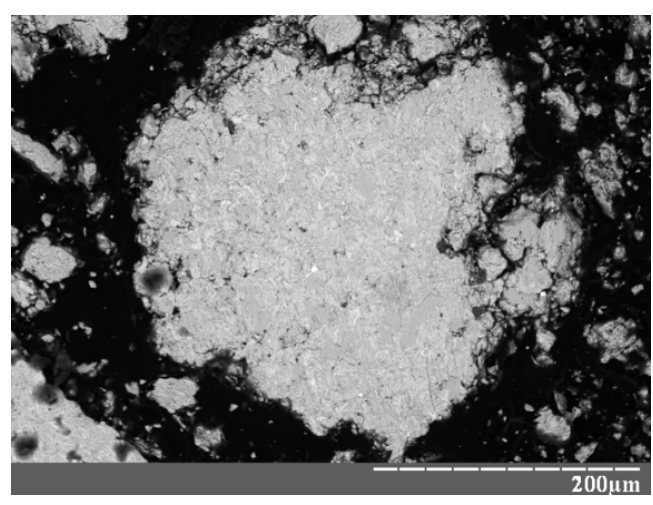

$b$

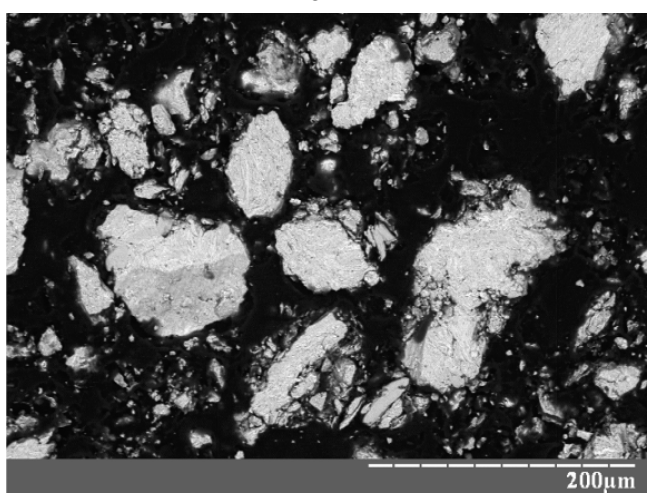

200

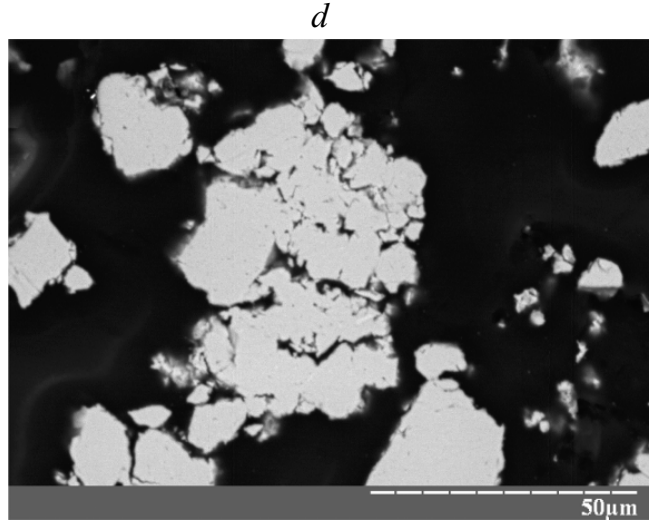

$f$

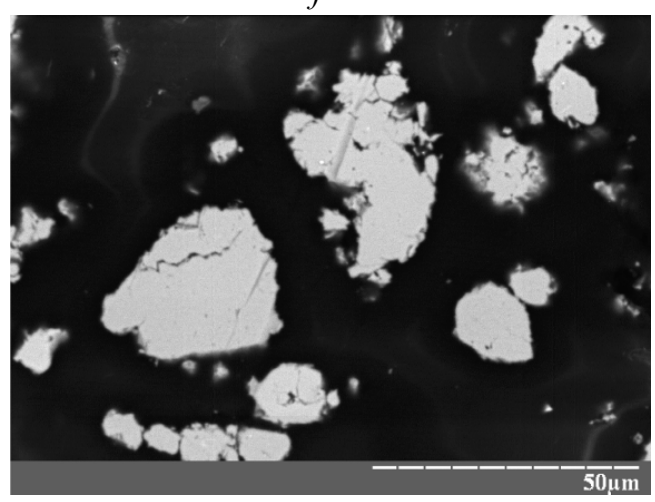

$h$

Fig. 1. Morphology $(a, c, e, g)$ and microstructure $(b, d, f, h)$ of powder particles of the AlCuNiFeCr $(a, b, e, f)$ and $\mathrm{AlCuNiFeTi}(c, d, g, h)$ alloys after grinding in a planetary-ball mill for $0.5(a-d), 5(e$, $f)$, and $15 \mathrm{~h}(g, h)$ 
TABLE 4. Chemical Composition of the AlCuNiFeTi and AlCuNiFeCr Alloys after Mechanical Activation

\begin{tabular}{|c|c|c|c|c|c|c|c|c|}
\hline \multirow{2}{*}{ Alloy } & \multirow{2}{*}{ Composition } & \multicolumn{6}{|c|}{ Element, at.\% } & \multirow{2}{*}{ VEC, e/a } \\
\hline & & $\mathrm{Al}$ & $\mathrm{Cu}$ & $\mathrm{Ni}$ & $\mathrm{Fe}$ & $\mathrm{Ti}$ & $\mathrm{Cr}$ & \\
\hline \multirow[t]{2}{*}{$\mathrm{AlCuNiFeTi}$} & Nominal & 20 & 20 & 20 & 20 & 20 & - & 7.20 \\
\hline & Experimental & 18.85 & 18.74 & 21.37 & 20.43 & 20.61 & - & 7.20 \\
\hline \multirow[t]{2}{*}{$\mathrm{AlCuNiFeCr}$} & Nominal & 20 & 20 & 20 & 20 & - & 20 & 7.60 \\
\hline & Experimental & 18.55 & 21.71 & 17.93 & 22.37 & - & 19.44 & 7.68 \\
\hline
\end{tabular}
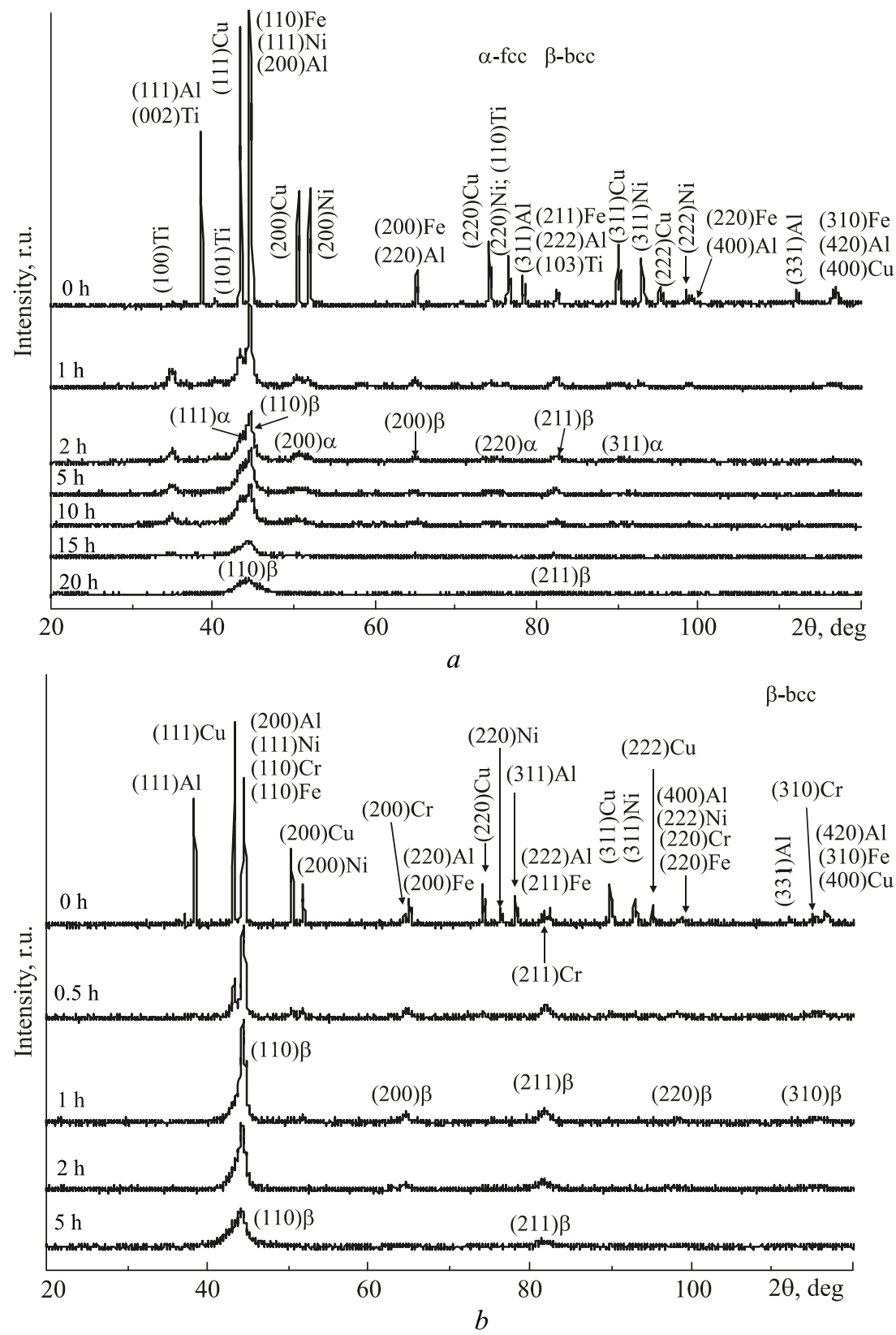

Fig. 2. X-ray diffraction spectra for the $\mathrm{AlCuNiFeTi}(a)$ and $\mathrm{AlCNiFeCr}(b)$ alloys at different mechanical activation stages 
displays superposed reflections of pure components. With increasing grinding time, the diffraction peaks of all components become much less intensive, the lines belonging to Al being the first to disappear. Following $1 \mathrm{~h}$ grinding, no aluminum peaks remain in the diffraction pattern for the $\mathrm{Al}-\mathrm{Cu}-\mathrm{Ni}-\mathrm{Fe}-\mathrm{Ti}$ powder mixture. Having the lowest melting point, aluminum is likely to easily dissolve in the other components. The diffraction peaks of the other components become so diffuse and weak that they are difficult to distinguish at large diffraction angles. In addition, adjacent reflections of various components overlap. The abnormal weakening of the diffraction peaks compared to the background intensity and their substantial broadening result from significant lattice distortion in the solid solution being formed. The lattice distortion is caused by atoms with different radii present in the solution and by nanocrystalline structure with high microstresses induced by severe plastic deformation in the MA process [14, 15]. In turn, the nanocrystalline structure is a prerequisite for the mechanical activation to begin as the diffusion coefficients of the powder mixture components increase substantially.

Following $2 \mathrm{~h} \mathrm{MA}$, fcc and bcc solid solutions ( $\alpha$ and $\beta$ phases) simultaneously form in the $\mathrm{Al}-\mathrm{Cu}-\mathrm{Ni}-\mathrm{Fe}-$ Ti system, which is evidenced by changes in the diffraction spectrum. The $\mathrm{Cu}$ and Ni peaks merge (fcc solid solution forms) and the Fe peaks shift to smaller angles as iron forms a bcc solid solution, the Ti peaks still being present in the pattern. The lattice parameters of the fcc and bcc solid solutions calculated from the positions of (220) $\alpha$ and (211) $\beta$ centers of gravity are $a=0.3564 \mathrm{~nm}$ and $a=0.2883 \mathrm{~nm}$, respectively. When MA time increases to 5 and $10 \mathrm{~h}$, the phase composition of the alloy does not change, but the structure refines further and microstresses grow in the solid solutions and individual components (Ti), which is testified by gradual weakening and broadening of the diffraction peaks (Fig. 2). Following $10 \mathrm{~h} \mathrm{MA}$, the lattice parameters of the fcc and bcc solid solutions were $a=0.3573$ and $a=0.2905 \mathrm{~nm}$.

When MA time increases to $15 \mathrm{~h}$, the reflections from Ti and fcc solid solution ( $\alpha$ phase) disappear. The alloy becomes single-phase with a bcc lattice and increased $a=0.2914 \mathrm{~nm}$ compared to the previous value. This indicates that the residual Ti and $\alpha$ phase dissolve in the Fe-based bcc solid solution ( $\beta$ phase). After $20 \mathrm{~h} \mathrm{MA}$, the lattice parameter of the bcc solid solution hardly changes, testifying that the MA process is complete and mixture components have fully dissolved in each other. It is very difficult to evaluate the average size of AlCuNiFeTi alloy crystallites at different MA stages from the broadening of diffraction peaks because the first lines belonging to the $\alpha$ and $\beta$ phases (fcc and bcc solid solutions) cannot be clearly separated.

Contrastingly to $\mathrm{AlCuNiFeTi}$, the $\mathrm{AlCuNiFeCr}$ high-entropy alloy forms much faster (Fig. 2b). When the diffraction peaks of the powder mixture components disappear, it can be considered that the solid solution begins to form. Following $1 \mathrm{~h}$ grinding, $\mathrm{Al}, \mathrm{Cu}$, and $\mathrm{Ni}$ almost completely dissolve in $\mathrm{Fe}$ and $\mathrm{Cr}$, which is evidenced by the absence of respective lines in the X-ray diffraction pattern (Fig. $2 b$ ). The bcc solid solution simultaneously forms from iron and chromium, having unlimited mutual solubility. Only the most intensive peaks can be found in the diffraction spectrum after powder grinding $(2 \mathrm{~h})$ in a planetary-ball mill, which indicates that the solid solution has a completely formed structure. When grinding time increases to $5 \mathrm{~h}$, no substantial changes in the alloy diffraction spectrum are observed. The alloy phase composition remains unchanged. The diffraction pattern further shows weakening and even greater broadening of the peaks, being strong evidence of a nanocrystalline solid solution with high microstresses (lattice distortions) induced by severe plastic deformation in the MA process [14, 16].

The size of crystallites (CSDs) and microstresses in the $\mathrm{AlCuNiFeCr}$ equiatomic alloy at different stages were calculated from the broadening of reflection lines (Table 5). With increasing grinding time, the average

TABLE 5. Size of Crystallites, Microstresses, and Lattice Parameter of the AlCuNiFeCr Alloy at Different Mechanical Activation Stages

\begin{tabular}{|c|c|c|c|}
\hline Grinding time, $\mathrm{h}$ & Size of crystallites, $\mathrm{nm}$ & Microstresses, $\%$ & Lattice parameter $a, \mathrm{~nm}$ \\
\hline 0.5 & 57 & 0.29 & - \\
1 & 38 & 0.38 & 0.2889 \\
2 & 24 & 0.52 & 0.2894 \\
5 & 17 & 0.63 & 0.2892 \\
\hline
\end{tabular}


crystallite size decreases: it is $17 \mathrm{~nm}$ after $5 \mathrm{~h}$ grinding. Following $6 \mathrm{~h} \mathrm{MA}$, the size of crystallites hardly changes, being evidence of balanced refinement and cold welding processes [16]. The crystallites do not refine further with longer MA process. Microstresses in the powder alloy yet become higher with longer MA. After $5 \mathrm{~h}$ grinding in a planetary-ball mill, microstresses reached $0.63 \%$. It is clear that the level of microstresses increases for three reasons: different sizes of interacting components (Table 2), growth of volume content of grain boundaries, and mechanical deformation. With longer grinding time, the volume content of grain boundaries and cumulative strain continuously increase as the crystallite size decreases. Lattice deformation (microstresses) can also grow when the density of dislocations generated in severe plastic deformation during MA increases [16].

The lattice parameters for the bcc solid solution calculated from the position of the (211) $\beta$ center of gravity for different MA times are summarized in Table 5. Following $2 \mathrm{~h}$ MA, $a=0.2894 \mathrm{~nm}$.

From a kinetic standpoint, $\mathrm{Cu}$ and $\mathrm{Ni}$, like $\mathrm{Al}$, are elements with a lower melting point (Table 1) in the studied alloys and thus they dissolve easier in early MA stages. The slower dissolution of $\mathrm{Fe}$ and $\mathrm{Ti} / \mathrm{Cr}$ is associated with greater bonding energy (highest melting point) compared to the other elements of quinary alloys and hence lower diffusion mobility in the MA process. From a thermodynamic standpoint, $\mathrm{Cu}$ and $\mathrm{Ni}$ form a stable fcc structure with transition metals, while $\mathrm{Al}$ forms a stable bcc structure through directed $p-d$ hybrid orbitals. In contrast to densely packed fcc and hcp structures, the bcc structure is more open (packing factor 0.68); hence, other elements dissolve easier in the bcc structure to form a substitutional solid solution, without significant expansion of the crystal lattice. For this reason, all mixture elements dissolve in $\mathrm{Fe}$ and $\mathrm{Cr}$, possessing a more open bcc structure.

Table 2 shows the mixing enthalpies $\Delta H$ for various potential atomic pairs of metals in the AlCuNiFeTi and $\mathrm{AlCuNiFeCr}$ high-entropy alloys. The atomic pairs generally have both positive and negative enthalpy significantly differing from zero. It is believed that only atomic pairs with near-zero mixing enthalpy can show high solid-state solubility [17]. In other words, most components of the AlCuNiFeTi and AlCuNiFeCr HEAs have limited solidstate solubility in equilibrium conditions. However, a supersaturated, simple bcc solid solution forms during MA of the powder mixture. The greater solid-state solubility is due to the high mixing entropy and nonequilibrium MA process. When the number of alloy components increases, the high mixing entropy intensifies random diffusion between different elements, leading to greater solid-state solubility. Additionally, the high mixing entropy decreases the tendency to ordering and segregation, facilitating the formation of solid solutions and increasing their stability as compared with intermetallic and other ordered phases. The MA process can also extend the solubility range of components in solid state. Activation occurs when crystallites become smaller than $100 \mathrm{~nm}$ and energy increases owing to a great volume content of grain boundaries in nanocrystalline alloys. The energy accumulated in grain boundaries serves as a driving force for forming the solid solution [18] and, consequently, its increase extends the solid-state solubility range. Longer grinding time enhances the interdiffusion of components and increases their solid-state solubility to the supersaturation stage, beyond which solubility no longer increases [16].

Structure and Phase Composition of AlCuNiFeCr and AlCuNiFeTi Equiatomic High-Entropy Alloys Following Pressure Sintering. The mechanically activated AlCuNiFeTi and AlCuNiFeCr HEAs undergo phase transformations when subjected to pressure sintering, which is evidenced by changes in the diffraction spectrum of the sintered alloys. The diffraction patterns for the sintered samples (Fig. 3) show weaker peaks besides intensive peaks belonging to the bcc solid solution ( $\beta$ phase). These weaker peaks correspond to two fcc solid solutions differing in lattice parameters $-\alpha$ and $\alpha_{1}$ phases. We assume that the $\alpha$ and $\alpha_{1}$ phases observed in the consolidated samples also existed in the powder alloys produced by mechanical activation. However, they could not be revealed because their amount was insignificant and the diffraction peaks were very diffuse and overlapped each other, resulting from nanocrystalline structure and strong lattice imperfection. Moreover, VEC of the alloys varies between 6.87 and $8 \mathrm{e} / \mathrm{a}$ (Table 3). This indicates that both bcc and fcc solid solutions can be formed.

The phase transformations (separation of two phases from the $\beta$ phase: $\alpha$ and $\alpha_{1}$ ) are attributed to metastable state of the supersaturated bcc solid solutions ( $\beta$ phases) produced by severe plastic deformation in the MA process. When being sintered, the $\beta$ phases transform to stable equilibrium phases- $-\mathrm{bcc}$ and fcc solid solutions. This is confirmed by the fact that lattice parameters of the bcc solid solutions ( $\beta$ phases) in the AlCuNiFeTi and $\mathrm{AlCuNiFeCr}$ alloys decrease by 0.0019 and $0.0015 \mathrm{~nm}$ after sintering as compared with those after MA and 


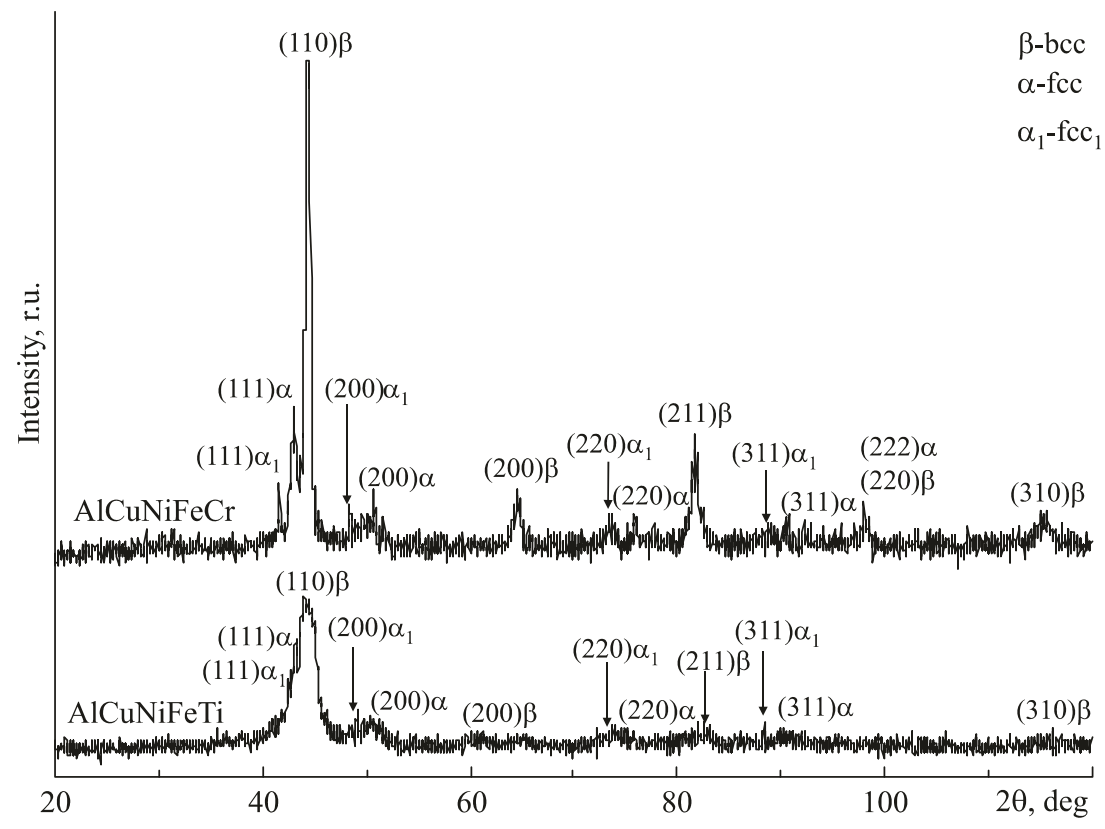

Fig. 3. X-ray diffraction spectra for the $\mathrm{AlCuNiFeTi}$ and $\mathrm{AlCuNiFeCr}$ powder alloys after sintering at $5 \mathrm{GPa}$ and $1073 \mathrm{~K}$

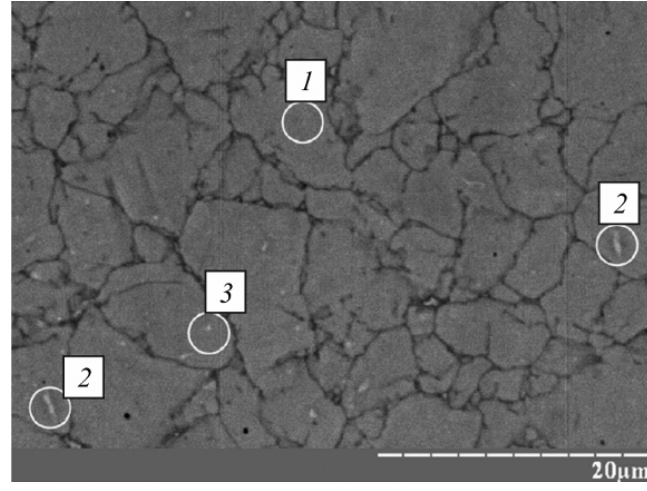

$a$

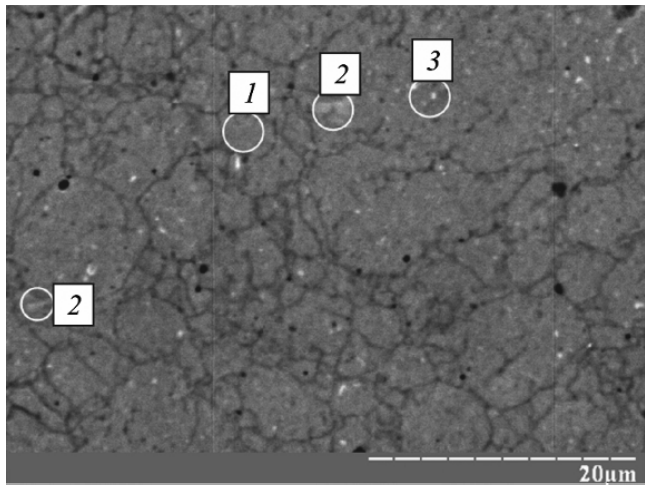

$b$

Fig. 4. Microstructure of the $\mathrm{AlCuNiFeTi}(a)$ and $\mathrm{AlCuNiFeCr}(b)$ powder alloys after pressure sintering

TABLE 6. Chemical Composition of Phases in the AlCuNiFeTi and AlCuNiFeCr Powder Alloys after Pressure Sintering

\begin{tabular}{|c|c|c|c|c|c|c|c|c|}
\hline \multirow{2}{*}{ Alloy } & \multirow{2}{*}{ Phase } & \multicolumn{6}{|c|}{ Chemical composition, at.\% } & \multirow{2}{*}{ VEC, e/a } \\
\hline & & $\mathrm{Al}$ & $\mathrm{Cu}$ & $\mathrm{Fe}$ & $\mathrm{Ni}$ & $\mathrm{Ti}$ & $\mathrm{Cr}$ & \\
\hline \multirow[t]{4}{*}{ AlCuNiFeTi } & Total & 19.7 & 19.9 & 20.7 & 19.9 & 19.8 & - & 7.2 \\
\hline & 1 & 22.6 & 9.80 & 29.6 & 16.2 & 21.8 & - & 6.6 \\
\hline & 2 & 13.5 & 31.4 & 15.8 & 24.6 & 21.8 & - & 8.5 \\
\hline & 3 & 11.7 & 42.6 & 13.2 & 22.9 & 9.60 & - & 8.8 \\
\hline \multirow[t]{4}{*}{$\mathrm{AlCuNiFeCr}$} & Total & 19.6 & 19.9 & 21.0 & 19.8 & - & 19.7 & 7.6 \\
\hline & 1 & 22.9 & 8.50 & 30.2 & 13.2 & - & 25.2 & 6.9 \\
\hline & 2 & 12.1 & 39.4 & 10.6 & 25.2 & - & 12.7 & 8.8 \\
\hline & 3 & 9.80 & 45.9 & 10.3 & 23.3 & - & 10.7 & 9.1 \\
\hline
\end{tabular}


constitute 0.2885 and $0.2877 \mathrm{~nm}$. This indicates that elements separate from the bcc phase to form two fcc solid solutions ( $\alpha$ and $\alpha_{1}$ phases) during sintering. Comparing the intensities of diffraction lines shows that the bcc solid solution is the major alloy component and amounts of the two fcc phases is insignificant. The fcc phase content of the $\mathrm{AlCuNiFeTi}$ alloy is substantially lower than that $(\leq 5 \%)$ of the $\mathrm{AlCuNiFeCr}$ alloy. Moreover, more intensive and less diffuse reflections, especially for the $\mathrm{AlCuNiFeCr}$ alloy, result from crystallite coarsening and internal energy release in the sintering process. The intensity and width of AlCuNiFeTi diffraction peaks change insignificantly, i.e., the alloy remains nanocrystalline after sintering, which is ascertained by very diffuse peaks of all its phases (Fig. 3).

The higher thermal stability of AlCuNiFeTi structure and phase composition, compared to AlCuNiFeCr, can be explained by the slowdown of diffusion processes during sintering. This results from stronger distortion of the bcc lattice in the dissolution of $\mathrm{Ti}$ atoms having greater atomic radius than $\mathrm{Cr}$ atoms (Table 1).

Scanning electron microscopy of the $\mathrm{AlCuNiFeTi}$ and $\mathrm{AlCuNiFeCr}$ alloys after pressure sintering revealed (Fig. 4) three phases: predominant dark gray (1), light gray (2), and white (3) phases. According to local chemical analysis (Table 6), the three phases of the sintered alloys contain all elements introduced into the starting powder mixture and present in powder HEAs after MA. However, they underwent quantitative redistribution during sintering. The dark gray phase in the AlCuNiFeTi alloy is rich in $\mathrm{Fe}$, Ti, and $\mathrm{Al}$ (Fig. 4, point 1 ) and in the $\mathrm{AlCuNiFeCr}$ alloy in $\mathrm{Cr}, \mathrm{Fe}$, and Al. The light gray phase (Fig. 4, point 2) in the AlCuNiFeTi alloy is rich in $\mathrm{Cu}$, $\mathrm{Ni}$, and $\mathrm{Ti}$ and in the $\mathrm{AlCuNiFeCr}$ alloy in $\mathrm{Cu}$ and $\mathrm{Ni}$. The white phase (Fig. 4, point 3 ) of both alloys is rich in $\mathrm{Cu}$ and $\mathrm{Ni}$.

Considering the peak intensity ratio of the $\beta, \alpha$, and $\alpha_{1}$ phases in the X-ray diffraction spectra (Fig. 3), volume contents of the phases in SEM images (Fig. 4), and chemical analysis results (Table 6), we can conclude that dark gray phase 1 in both alloys belongs to the bcc solid solution ( $\beta$ phase), and the white and light gray phases (smaller volume content) to the fcc and $\mathrm{fcc}_{1}$ solid solutions ( $\alpha$ and $\alpha_{1}$ phases) with different lattice parameters.

Numerous intermetallics (e.g., $\mathrm{Ni}_{3} \mathrm{Al}, \mathrm{Ni}_{3} \mathrm{Fe}, \mathrm{Fe}_{3} \mathrm{Al}, \mathrm{Al}_{3} \mathrm{Fe}, \mathrm{TiAl}, \mathrm{Al}_{3} \mathrm{Ti}, \mathrm{Ni}{ }_{2} \mathrm{Cr}, \mathrm{CrAl}_{7}, \mathrm{Cr}_{2} \mathrm{Al}_{11}, \mathrm{CrAl}_{14}$, $\mathrm{Cr}_{2} \mathrm{Al}, \mathrm{Cr}_{5} \mathrm{Al}_{8}$ ) are observed in conventional $\mathrm{Al}-\mathrm{Cu}-\mathrm{Ni}-\mathrm{Fe}-\mathrm{Ti} / \mathrm{Cr}$ alloys, while they do not form in the AlCuNiFeTi and $\mathrm{AlCuNiFeCr}$ high-entropy quinary alloys. They consist completely of simple bec and fec solid solutions, and the total number of phases in them is much lower than the maximum equilibrium one allowed by the Gibbs phase rule. The prevalence of simple solid solutions over intermetallics in the multicomponent equiatomic alloys is mainly due to high mixing entropy $[1,8]$. Considering the principles of thermodynamics, phases with low Gibbs energy $G$ are more favored:

$$
G=H-T S,
$$

where $H$ is enthalpy, $T$ is absolute temperature, and $S$ is entropy. Should the enthalpy be constant, phases with higher entropy will have lower free Gibbs energy. This entropy has a greater effect on HEAs. The AlCuNiFeTi and $\mathrm{AlCuNiFeCr}$ alloys contain five components each and their mixing entropy is $>1.61 R$, which is very high for metallic alloys (mixing entropy of conventional metallic alloys ranges from $0.69 R$ to $1.32 R$ ). Moreover, the entropy of solid solutions is much higher than that of intermetallics. The solid solutions are more chaotic and intermetallics more ordered. In this regard, free Gibbs energy of the solid solutions is lower than that of the intermetallics, thus promoting the formation of solid solutions. The entropy of individual elements present in the alloy (Table 1) is lower than the mixing entropy of quinary systems $\left(13.38 \mathrm{~J} \cdot \mathrm{K}^{-1} \cdot \mathrm{mol}^{-1}\right)$; hence, solid solutions with simple crystal structure are formed.

Mechanical Properties of Sintered Alloys. The tests involving continuous indentation under a load of $1.5 \mathrm{~N}$ revealed that hardness of the $\mathrm{AlCuNiFeTi}$ and $\mathrm{AlCuNiFeCr}$ alloys after pressure sintering was $H_{\mathrm{IT}}=11.8$ and $10.5 \mathrm{GPa}$, reduced elastic modulus was $E_{\mathrm{r}}=127$ and $148 \mathrm{GPa}$, elastic strain $\varepsilon_{\mathrm{es}}=3.04$ and $2.36 \%$, and yield stress $\sigma_{\mathrm{es}}=3.62$ and 3.22 GPa. Similar ratios were observed for as-cast HEAs based on bcc solid solutions including components with substantially different atomic radii [19].

The Vickers hardness of the sintered alloys measured on the restored impression using a PMT-3 hardness meter under an indenter load of $1.5 \mathrm{~N}$ was $H V=11.2 \pm 0.3 \mathrm{GPa}$ for the AlCuNiFeTi alloy and $H V=9.2 \pm 0.25$ for 
$\mathrm{AlCuNiFeCr}$. Hence, $H V$ of the quinary alloys is much greater than the hardness of starting components $\mathrm{Al}, \mathrm{Cu}, \mathrm{Ni}$, $\mathrm{Fe}, \mathrm{Ti}, \mathrm{Cr} \quad(0.21-1.3 \mathrm{GPa})$ and 8.5 times higher than the hardness of chromium, being the hardest among them.

The high strength characteristics of the AlCuNiFeTi and AlCuNiFeCr HEAs alloys produced by mechanical activation followed by pressure sintering are due to solid-solution hardening and strong lattice distortion resulting from different atomic radii of substitutional elements (composition factor of lattice strengthening), nanostructured state (structural factor), prevailing bec phase, and a small content of two fcc phases.

\section{CONCLUSIONS}

Mechanical activation has been employed to synthesize nanocrystalline equiatomic $\mathrm{AlCuNiFeTi}$ and AlCuNiFeCr HEAs consisting of supersaturated substitutional solid solutions with bcc crystal structure. High mixing entropy decreases free Gibbs energy of the AlCuNiFeTi and $\mathrm{AlCuNiFeCr}$ equiatomic alloys, reducing the tendency to ordering and segregation, facilitates the formation of a solid solution, and increases its stability compared to intermetallics and other ordered phases.

After sintering at $5 \mathrm{GPa}$ and $1073 \mathrm{~K}$ for $0.5 \mathrm{~h}$, the alloys become three-phase and consist of a bcc solid solution matrix with fine inclusions (to $5 \%$ ) of two fcc solid solutions with different lattice parameters. The $\mathrm{AlCuNiFeTi}$ alloy remains nanostructured, which indicates that it has higher thermal stability than AlCuNiFeCr.

After pressure sintering, the $\mathrm{AlCuNiFeTi}$ and $\mathrm{AlCuNiFeCr}$ high-entropy alloys have high strength characteristics shown by none of the starting components, which are due to solid-solution and nanostructured hardening.

\section{REFERENCES}

1. J. W. Yeh, S. K. Chen, S. J. Lin, et al., "Nanostructured high-entropy alloys with multiple principal elements: novel alloy design concepts and outcomes," J. Adv. Eng. Mater., 6, No. 5, 299-303 (2004).

2. S. Ranganathan, "Alloyed pleasures: multimetallic cocktails," Curr. Sci., 85, No. 10, 1404-1406 (2003).

3. J. W. Yeh, Y. L. Chen, and S. J. Lin, "High-entropy alloys-a new era of exploitation," Mater. Sci. Forum, 560, 1-9 (2007).

4. J. H. Pi, Y. Pan, L. Zhang, et al., "Microstructure and property of AlTiCrFeNiCu high-entropy alloy," $J$. Alloys Compd., 18, No. 509, 5641-5645 (2011).

5. X. Yang, Y.Zhang, and P. K. Liaw, "Microstructure and compressive properties of $\mathrm{NbTiVTaAl}_{x}$ high entropy alloys," Proc. Eng., 36, 292-298 (2012).

6. S. A. Firstov, V. F. Gorban', N. A. Krapivka, et al., "Mechanical properties of as-cast multicomponent alloys are high temperatures," Sovr. Probl. Fiz. Materialoved., Issue 17, 126-139 (2008).

7. O. V. Sobol', A. A. Andreev, V. F. Gorban', et al., "On the method for analyzing structurally stressed state of vacuum arc coatings in the multielement high-entropy $\mathrm{Ti}-\mathrm{V}-\mathrm{Zr}-\mathrm{Nb}-\mathrm{Hf}$ system and superhard nitrides on its basis," Pis'ma Zh. Tekh. Fiz., 38, No. 13, 41-46 (2012).

8. S. Guo and C. T. Liu, "Phase stability in HEAs: formation of solid-solution phase or amorphous phase," Progr. Mater. Sci.: Mater. Int., No. 21, 433-446 (2011).

9. F. R. de Boer, R. Boom, W. C. M. Mattens, et al., Cohesion in Metals, Elsevier Science Publisher, New York (1988), p. 482.

10. V. F. Gorban', V. A. Nazarenko, N. I. Danilenko, et al., "Effect of deformation on the structure and mechanical properties of the $\mathrm{Fe}_{25} \mathrm{Cr}_{20} \mathrm{Ni}_{20} \mathrm{Co}_{10} \mathrm{Mn}_{15} \mathrm{Al}_{10}$ high-entropy alloy," Deform. Razrush. Mater. No. 9, 2-6 (2013).

11. Ya. S. Umanskii, Yu. A. Skakov, A. N. Ivanov, et al., Crystallography, X-Ray Diffraction, and Electron Microscopy [in Russian], Metallurgiya, Moscow (1982), p. 632.

12. S. R. Ignatovich and I. M. Zakiev, "Universal Micron Gamma micro/nanoindentation meter," Zavod. Lab., 77, No. 1, 61-67 (2011).

13. S. A. Firstov, V. F. Gorban', and É. P. Pechkovskii, "Automated indentation to establish ultimate hardness, elastic strain, and associated stress of materials," Materialovedenie, No. 8, 15-21 (2008). 
14. S. Varalakshmi, M. Kamaraj, and B. S. Murty, "Formation and stability of equiatomic and nonequiatomic nanocrystalline CuNiCoZnAlTi high-entropy alloys by mechanical alloying," Metall. Mater. Trans. A, 10, No. 41, 2703-2709 (2010).

15. N. I. Noskova and R. R. Mulyukov, Submicrocrystalline and Nanocrystalline Metals and Alloys [in Russian], Ural. Otdel. Ros. AN, Ekaterinburg (2003), p. 279.

16. C. Suryanarayana, "Mechanical alloying and milling," Progr. Mater. Sci., 46, 1-184 (2001).

17. A. Takeuchi and A. Inoue, "Quantitative evaluation of critical cooling rate for metallic glasses," Mater. Sci. Eng. A, 304-306, 446-451 (2001).

18. K. B. Zhang, Z. Y. Fu, J. Y. Zhang, et al., "Nanocrystalline CoCrFeNiCuAl high-entropy solid solution synthesized by mechanical alloying," J. Alloys Compd., 485, No. 1-2, 31-34 (2009).

19. S. A. Firstov, V. F. Gorban', N. A. Krapivka, et al., "Strengthening and mechanical properties of as-cast high-entropy alloys," Kompoz. Nanostruct., No. 2, 5-20 (2012). 